\title{
The DC Bias Model and Simulation Analysis of Three-phase Three-limps Transformer Based on EIC Principle
}

\author{
Wenfeng $\mathrm{Li}^{1, \mathrm{a}}$, Hongkun Bai ${ }^{1, \mathrm{~b}}$, Fusheng Zhang ${ }^{1, \mathrm{c}}$, Fangmin Bao ${ }^{1, \mathrm{~d}}$ \\ Yubin Mao ${ }^{1, e}$, Yongmin Liu 1, f, Feifei Bo 1, g, Yuanpeng Hua 1, h, Ding Han 1, i, \\ Yaoyu Yang ${ }^{2, j}$ \\ ${ }^{1}$ State Grid Henan Electric Power Company Institute of Economics and Technology, Henan \\ 450000, China. \\ 2 Zhengzhou University, Henan 450000, China. \\ a809406879@qq.com, b1420254015@qq.com, c zhfs@163.com, d baofangmin@ha.sgcc.com.cn, \\ eYb_mao@163.com, ${ }^{\mathrm{f} l i u a m i n @ 163 . c o m, ~}{ }^{\mathrm{g}}$ bofeifei272@163.com, ${ }^{\mathrm{h}}$ 13783661352@163.com, \\ i913023263@qq.com, j502376698@qq.com,
}

\begin{abstract}
In this paper, the model of transformer DC bias simulation is established based on EIC principle. This model considers the hysteresis loss and eddy current loss of the transformer core through the J-A model and the Bertotti theory. Based on this model, the effects of DC bias on the operating characteristics of single-phase transformers are analyzed. Moreover, this paper summarizes the variation of field current and leakage flux as well.
\end{abstract}

Keywords: Transformer model, DC bias, Harmonic, J-A model, Bertotti theory.

\section{Introduction}

When the ultra HVDC transmission is operated in a monopole operation mode with earth return, strong DC power may cause DC bias in nearby transformers, resulting in greatly increased saturation of the core, highly distorted excitation current, increased reactive power loss, and increased temperature rise, protection against erroneous actions and other serious threats to the safe and stable operation of AC-DC hybrid power grids [1-2].

In view of this, some scholars have established a magnetic coupling model of the transformer circuit [3], described the magnetization curve of the transformer core by an empirical formula, proposed a frequency-dependent nonlinear reluctance calculation formula of the core, and established a model in the frequency domain. Some scholars have established an integrated circuit model of transformer based on the dual principle. Only one circuit can be used to represent the electromagnetic behavior of the entire transformer, but the duality theory is only applicable to transformers with a planar magnetic topology, which limits the application of this model.

In this paper, considering the key elements of core hysteresis curve, core hysteresis and turbine effect, core topological structure and so on, using EIC principle, J-A model and Bertotti theory to build a three-phase three-limps transformer model to solve the conflict between accuracy and complexity effectively. Based on this model, the effect of DC bias on the operation characteristics of three-phase three-limps transformer was analyzed, and the variation law of excitation current, leakage flux, and core flux were summarized.

\section{Description of the Models}

\subsection{Establish Circuit Model Based on Three-Phase Three-Limps Transformer Core Topology and Transformer Parameters}

Nonlinear resistance characterization of transformer core eddy current losses

Set $1_{p}, d, A_{p}, \tau, \sigma, B_{p}$, are the number of turns, the length, the thickness, the crosssectional area of the core lamination and the lamination width, the conductivity and the magnetic induction, respectively. 
According to Bertotti's theory, the instantaneous power loss of the core transformer core is:

$$
\begin{aligned}
& \mathrm{P}_{\mathrm{c}}=\mathrm{H}_{\mathrm{c}} \frac{\mathrm{dB}}{\mathrm{dt}} \mathrm{A}_{\mathrm{c}} \mathrm{l}_{\mathrm{c}} \\
& =\frac{\frac{\sigma \mathrm{d}^{2} l_{\mathrm{c}}}{12 \mathrm{~A}_{\mathrm{c}}}+\left(\frac{\mathrm{Gd} \tau \mathrm{H}_{0} \sigma \mathrm{l}_{\mathrm{c}}^{2}}{\mathrm{~A}_{\mathrm{c}}}\right)^{0.5}\left(\frac{\mathrm{d} \Phi}{\mathrm{dt}}\right)^{-0.5}}{\mathrm{~N}_{1}^{2}}\left(\mathrm{~N}_{1} \frac{\mathrm{d} \Phi}{\mathrm{dt}}\right)^{2} \\
& =\frac{\mathrm{k}_{\mathrm{c}}}{\mathrm{N}_{1}^{2}}\left(\mathrm{~N}_{1} \frac{\mathrm{d} \Phi}{\mathrm{dt}}\right)^{2}
\end{aligned}
$$

Among them, $\mathrm{H}_{\mathrm{c}}$ denotes magnetic field strength related to core eddy current, the dimensionless constant $\mathrm{G}=0.1356, \mathrm{H}_{0}$ is related to the internal potential caused by the magnetic domain wall of the iron core lamination, and is generally related to the maximum magnetic induction intensity $\mathrm{B}_{\max }$. $\mathrm{N}_{1} \mathrm{~d} \Phi / \mathrm{dt}$ has the dimension of voltage, so $\mathrm{k}_{\mathrm{c}} / \mathrm{N}_{1}^{2}$ has the reciprocal of the resistance dimension, that is $\Omega^{-1}$, the core eddy current loss can be characterized as:

$$
\mathrm{r}_{\mathrm{c}}=\mathrm{N}_{1}^{2} / \mathrm{k}_{\mathrm{c}}
$$

The magnetic potential generated by the eddy current can be written as $\mathrm{F}_{\mathrm{cp}}=\mathrm{H}_{\mathrm{c}} \mathrm{l}_{\mathrm{p}}$, which can be available as:

$$
\mathrm{F}_{\mathrm{cp}}=\mathrm{k}_{\mathrm{cp}}\left(\mathrm{d} \Phi_{\mathrm{p}} / \mathrm{dt}\right)
$$

The magnetomotive force acting on the primary and secondary winding currents and the eddy current of the iron core are:

$$
\begin{aligned}
& F=N_{1} i_{1}-N_{2} i_{2}-k_{c} \frac{d \Phi}{d t} \\
& =N_{1}\left[i_{1}-\frac{k_{c}}{N_{1}^{2}}\left(N_{1} \frac{d \Phi}{d t}\right)\right]-N_{2} i_{2} \\
& =N_{1} i_{1}^{\prime}-N_{2} i_{2}
\end{aligned}
$$

The Eq. (4) shows that the eddy current loss of the core can be represented by a non-linear resistor connected in parallel with the primary winding. According to the single-phase transformer core form and magnetic circuit model, the core eddy current loss resistance $r_{c}$ can be obtained.

Three-phase three-limps transformer circuit model

According to the above derivation, the three-phase three-limps transformer primary circuit model can be represented as $r_{c 1} 、 r_{c 2} 、 r_{c 3}$ and $r_{p 1} 、 r_{p 2} 、 r_{p 3}$ in parallel or in series with other parameters. The secondary circuit model can be represented as a series connection between the parameters. The circuit model can be shown in Fig. 1.

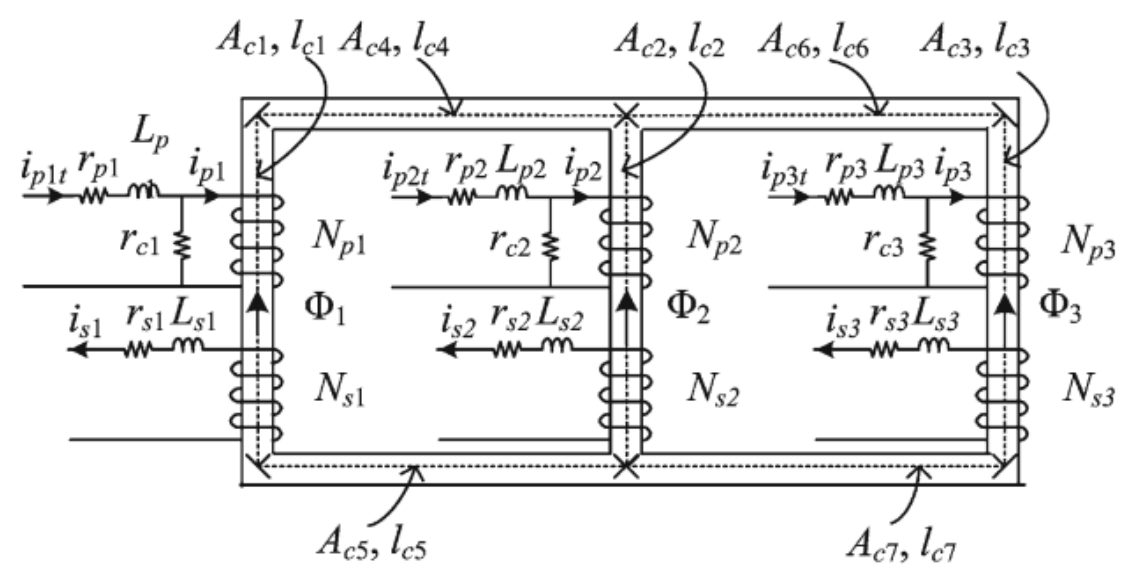

Fig. 1 Three-phase three-limps double-winding core type transformer core structure 
Among them, $A_{c i} 、 L_{c i}, N_{p} 、 N_{s}, i_{p} 、 i_{s}$ and $\Phi_{i}, r_{p}, r_{s}, r_{c}, L_{p} 、 L_{s}$ are the number of turns, core cross-sectional area, core length, primary and secondary winding turns, primary and secondary winding current, core flux, primary and secondary winding resistance, core eddy current loss resistance, primary and secondary winding inductance, respectively.

\subsection{Establish Differential Magnetic Circuit Model Based on Differential Magnetic Circuit Principle}

(1). Differential magnetic circuit principle

The transformer core magnetic branch shown in Fig. 1 can be obtained:

$$
\left\{\begin{array}{l}
\mathrm{f}_{\mathrm{i}}=\mathrm{R}_{\mathrm{mi}} \Phi_{\mathrm{i}}-\mathrm{F} \\
\mathrm{R}_{\mathrm{mi}} \Phi_{\mathrm{i}}=\mathrm{H}_{\mathrm{i}} 1_{\mathrm{ci}}
\end{array}\right.
$$

Among them, $f_{R m i}$ is the magnetic resistance corresponding magnetic pressure drop, $R_{m i}$ is the iron core effective magnetoresistance, $F$ is the magnetomotive force, $\Phi_{i}$ is the magnetic flux, $f_{i}$ is the branch magnetic pressure, $\Phi_{i}$ is the iron core magnetic flux.

Calculate derivative of time $t$ at both ends of the above formula shows that:

$$
\left\{\begin{aligned}
\mathrm{df}_{\mathrm{i}} / \mathrm{dt} & =\mathrm{d}\left(\mathrm{R}_{\mathrm{mi}} \Phi_{\mathrm{i}}\right) / \mathrm{dt}-\mathrm{dF} / \mathrm{dt} \\
& =\mathrm{R}_{\mathrm{mdi}}\left(\mathrm{d} \Phi_{\mathrm{i}} / \mathrm{dt}\right)-\mathrm{dF} / \mathrm{dt} \\
\mathrm{d}\left(\mathrm{R}_{\mathrm{mi}}\right. & \left.\Phi_{\mathrm{i}}\right) / \mathrm{dt}=\mathrm{d}\left(\mathrm{H}_{\mathrm{i}} 1_{\mathrm{ci}}\right) / \mathrm{dt} \\
& =1_{\mathrm{ci}} \mathrm{dH}_{\mathrm{i}} / \mathrm{dt} \\
& =1_{\mathrm{ci}}\left(\mathrm{dH}_{\mathrm{i}} / \mathrm{dB}_{\mathrm{i}}\right)\left(\mathrm{dB}_{\mathrm{i}} / \mathrm{dt}\right) \\
& =1_{\mathrm{ci}} / \mathrm{A}_{\mathrm{ci}}\left(\mathrm{dH}_{\mathrm{i}} / \mathrm{dB}_{\mathrm{i}}\right)\left(\mathrm{d}_{\mathrm{i}} / \mathrm{dt}\right) \\
& =1_{\mathrm{ci}} /\left(\mathrm{A}_{\mathrm{ci}} \mu_{\mathrm{di}}\right)\left(\mathrm{d}_{\mathrm{i}} / \mathrm{dt}\right) \\
& =\mathrm{R}_{\mathrm{mdi}}\left(\mathrm{d} \Phi_{\mathrm{i}} / \mathrm{dt}\right)
\end{aligned}\right.
$$

Among them, $\mathrm{A}_{\mathrm{ci}}, \mathrm{L}_{\mathrm{ci}}, \mathrm{N}, \mathrm{i}$ are the number of turns, core cross-sectional area, core length, winding turns, and winding current, respectively. The differential permeability is $\mu_{\mathrm{di}}=\mathrm{dB}_{\mathrm{i}} / \mathrm{dH}_{\mathrm{i}}$, and the differential reluctance is $\mathrm{R}_{\mathrm{mdi}}=1_{\mathrm{ci}} /\left(\mu_{\mathrm{di}} \mathrm{A}_{\mathrm{ci}}\right)$. The first equation of Eq. (6) represents the relationship between branch magnetic pressure, branch flux, the rate of change of magnetomotive force, and the EIC principle.

(2). Establish transformer differential magnetic circuit model based on three-phase three-limps transformer parameters

For the three-phase three-limps transformer, the magnetic circuit model is shown in Fig. 2. Among them, $R_{m 1}, R_{m}, R_{m}, R_{m}, R_{m}, R_{m}$ and $R_{m} 7$ are core and yoke differential magnetic reluctance. $R_{m a}$, $\mathrm{R}_{\mathrm{ma} 0}, \mathrm{R}_{\mathrm{mb}}, \mathrm{R}_{\mathrm{mb}}, \mathrm{R}_{\mathrm{mc}}, \mathrm{R}_{\mathrm{mc}}$, $\mathrm{R}_{\mathrm{m} 01}, \mathrm{R}_{\mathrm{m} 01}, \mathrm{R}_{\mathrm{m} 02}, \mathrm{R}_{\mathrm{m} 03}$ are differential leakage resistance between windings. The corresponding differential flux are $\mathrm{d} \Phi_{\mathrm{ma}} / \mathrm{dt}, \mathrm{d} \Phi_{\mathrm{ma} 0} / \mathrm{dt}, \mathrm{d} \Phi_{\mathrm{mb}} / \mathrm{dt}, \mathrm{d} \Phi_{\mathrm{mb}} / \mathrm{dt}, \mathrm{d} \Phi_{\mathrm{mc}} / \mathrm{dt}$, $\mathrm{d} \Phi \mathrm{mc} 0 / \mathrm{dt}$ and $\mathrm{d} \Phi \mathrm{m} 0 / \mathrm{dt}$. The primary and secondary differential magnetomotive force of $\mathrm{A}, \mathrm{B}$, and C phases are $\mathrm{dF}_{\mathrm{p} 1} / \mathrm{dt}, \mathrm{dF}_{\mathrm{s} 1} / \mathrm{dt}, \mathrm{dF}_{\mathrm{p} 2} / \mathrm{dt}, \mathrm{dF}_{\mathrm{s} 2} / \mathrm{dt}, \mathrm{dF}_{\mathrm{p} 3} / \mathrm{dt}, \mathrm{dF}_{\mathrm{s} 3} / \mathrm{dt}$, respectively.

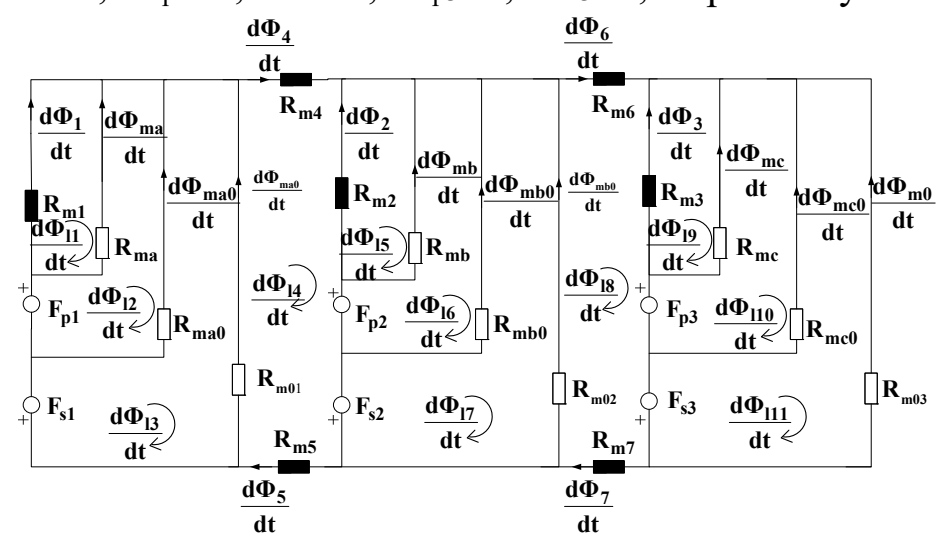

Fig. 2 Three-phase three-limps double-winding core-type transformer differential magnetic circuit model 
Differential magnetoresistance is obtained by a single core magnetization curve or a Jiles-Atherton model. For the Jiles-Atherton model, the differential permeability can be expressed as:

$$
\left\{\begin{array}{l}
\mu_{\mathrm{di}}=\mu_{0}\left(1+\mathrm{dM}_{\text {irri }} / \mathrm{dH}_{\mathrm{i}}+\mathrm{dM}_{\mathrm{revi}} / \mathrm{dH}_{\mathrm{i}}\right) \\
\frac{\mathrm{dM}_{\text {irri }}}{\mathrm{dH}_{\mathrm{i}}}=\frac{\mathrm{M}_{\text {ani }}-\mathrm{M}_{\text {irri }}}{\mathrm{k} \delta-\mathrm{a}_{1}\left(\mathrm{M}_{\text {ani }}-\mathrm{M}_{\text {irri }}\right)} \\
\frac{\mathrm{dM}_{\text {revi }}}{\mathrm{dH}_{\mathrm{i}}}=\mathrm{c}\left(\frac{\mathrm{dm}_{\text {ani }}}{\mathrm{dH}_{\mathrm{i}}}-\frac{\mathrm{dM}_{\text {irri }}}{\mathrm{dH}_{\mathrm{i}}}\right) \\
\mathrm{M}_{\mathrm{an}}(\mathrm{H})=\mathrm{M}_{\mathrm{s}}\left[\operatorname{coth}\left(\frac{\mathrm{H}+\alpha_{1} \mathrm{M}}{\alpha_{2}}\right)-\frac{\alpha_{2}}{\mathrm{H}+\alpha_{1} \mathrm{M}}\right] \\
\delta=\operatorname{sign}(\mathrm{dH} / \mathrm{dt})
\end{array}\right.
$$

Among them, $M_{\text {an }}, M_{s}, \alpha_{1}$ are the number of turns, non-hysteresis magnetization, saturation magnetization and mean field parameters, respectively. $\alpha_{2}$ Represents the shape of the nonhysteresis magnetization curve, $\mathrm{k}$ reflects the motion of the magnetic domain, $\mathrm{c}$ is the reversible susceptibility, and $0<\mathrm{c}<1$.

\subsection{Derive the Relationship of Core Differential Flux, Differential Magnetomotive Force, Flux Linkage and Loop Differential Flux Relationship Based on Differential Magnetic Model}

Based on the differential magnetic circuit model of the three-phase three-limps transformer, the relation between the differential flux matrix and the circuit differential flux matrix can be obtained:

$$
\frac{\mathrm{d}}{\mathrm{dt}}\left(\begin{array}{l}
\Psi_{\mathrm{p} 1} \\
\Psi_{\mathrm{p} 2} \\
\Psi_{\mathrm{p} 3} \\
\Psi_{\mathrm{s} 1} \\
\Psi_{\mathrm{s} 2} \\
\Psi_{\mathrm{s} 3}
\end{array}\right)=\left(\begin{array}{ccccccc}
\mathrm{N}_{\mathrm{p} 1} & 0 & 0 & 0 & 0 & 0 & 0 \\
0 & \mathrm{~N}_{\mathrm{p} 2} & 0 & 0 & 0 & 0 & 0 \\
0 & 0 & \mathrm{~N}_{\mathrm{p} 3} & 0 & 0 & 0 & 0 \\
-\mathrm{N}_{\mathrm{s} 1} & 0 & 0 & 0 & 0 & 0 & 0 \\
0 & -\mathrm{N}_{\mathrm{s} 2} & 0 & 0 & 0 & 0 & 0 \\
0 & 0 & -\mathrm{N}_{\mathrm{s} 3} & 0 & 0 & 0 & 0
\end{array}\right) \frac{\mathrm{d}}{\mathrm{dt}}\left(\begin{array}{c}
\Phi_{1} \\
\Phi_{2} \\
\Phi_{3} \\
\Phi_{4} \\
\Phi_{5} \\
\Phi_{6} \\
\Phi_{7}
\end{array}\right)
$$

\subsection{Based on the Conclusion of Step 2.3, Derivation of the Differential Inductance Matrix}

The differential inductance matrix is the bridge that connects the transformer magnetic circuit to the circuit, characterized the core saturation characteristics and hysteresis effect. The differential inductance matrix $\mathbf{L}_{\mathbf{d}}$ is:

$$
\mathbf{d} \Psi / \mathbf{d t}=\mathbf{L}_{\mathrm{d}}\left(\mathbf{d I} \mathbf{p s}_{\mathrm{ps}} / \mathbf{d t}\right)
$$

Among them, $\boldsymbol{\Psi}$ is the primary, secondary winding magnetic flux matrix, $\mathbf{I}_{\mathbf{p s}}$ is the primary, secondary winding current matrix.

Substituting (8)-(9) into (10) gives the differential inductance matrix $\mathbf{L}_{\mathbf{d}}$ :

$$
\begin{aligned}
\frac{d \Psi}{d t} & =N_{\Psi} \frac{d \Phi}{d t}=N_{\Psi} C\left(R^{-1} \frac{d F}{d t}\right) \\
& =N_{\Psi} C R^{-1}\left(N_{F} \frac{d I_{p s}}{d t}\right)=L_{d} \frac{d I_{p s}}{d t} \\
\Rightarrow L_{d} & =N_{\Psi} C R^{-1} N_{F}
\end{aligned}
$$

\subsection{Establish Single-Phase Transformer Group Circuit Model Based on Single-Phase Transformer Winding Connection Form}

Based on the above theory, a Y/Y-connected three-phase three-limps transformer is taken as an example, and a circuit magnetic circuit coupling equation is established to realize the DC bias magnetic simulation of the transformer. 


$$
\begin{aligned}
\left(\begin{array}{c}
\mathbf{E}_{\mathbf{p}} \\
\mathbf{E}_{\mathrm{s}}
\end{array}\right) & =\left(\begin{array}{c|c}
\mathbf{R}_{\mathrm{p}} & \mathbf{0} \\
\hline \mathbf{0} & \mathbf{R}_{\mathrm{s}}
\end{array}\right)\left(\begin{array}{c}
\mathbf{I}_{\mathrm{p}} \\
\mathbf{I}_{\mathrm{s}}
\end{array}\right)+\left(\begin{array}{c|c}
\mathbf{L}_{\mathrm{p}} & \mathbf{0} \\
\hline \mathbf{0} & \mathbf{L}_{\mathrm{s}}
\end{array}\right) \frac{\mathbf{d}}{\mathbf{d t}}\left(\begin{array}{c}
\mathbf{I}_{\mathrm{p}} \\
\mathbf{I}_{\mathrm{s}}
\end{array}\right) \\
& +\left(\begin{array}{c|c}
\mathbf{K}_{\mathrm{p}} & \mathbf{0} \\
\hline \mathbf{0} & \mathbf{K}_{\mathrm{s}}
\end{array}\right) \mathbf{L}_{\mathbf{d}} \mathbf{T} \frac{\mathbf{d}}{\mathbf{d t}}\left(\begin{array}{c}
\mathbf{I}_{\mathbf{p}} \\
\mathbf{I}_{\mathrm{s}}
\end{array}\right)
\end{aligned}
$$

Wherein $\mathrm{p}, \mathrm{s}$ represent the primary, secondary, $\mathbf{R}, \mathbf{L}$ are matrices of resistance and inductance matrix. $\mathrm{K}$ represents the unit matrix.

\section{Influence of DC Bias on Operation Characteristics of Single-Phase Transformer}

\subsection{Influence of DC Bias on Leakage Flux of Transformer}

The influence of DC bias on the single-phase transformer is calculated based on the external magnetic leakage resistance $\mathrm{R}$ of the high voltage winding of the transformer. The results are shown in Fig. 3(a) and (b).

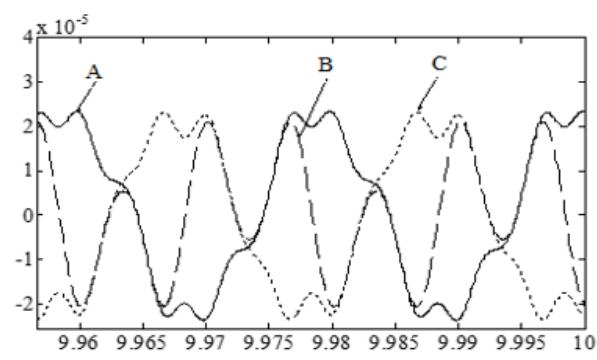

(a)

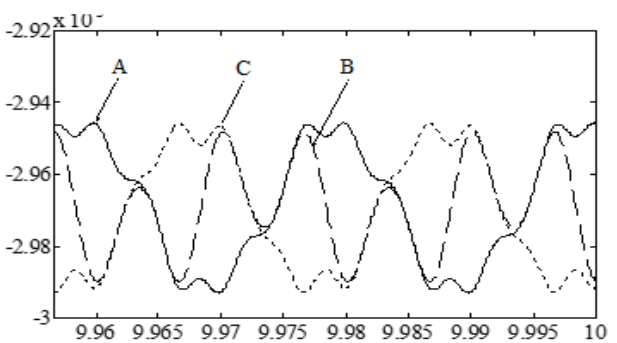

(b)

Fig. 3(a)/(b) Leakage flux at IDC $=0 / 24.8 \mathrm{~A}$

It can be seen that the DC bias magnetic flux has a great influence on the leakage flux amplitude of the three-phase three-limps transformer, so that the leakage flux is greatly increased, and the leakage flux waveform is similar to the shape of the excitation current waveform.

\subsection{Effect of DC Bias on Transformer Core Flux}

This section examines the effects of DC bias on the magnetic flux of a three-phase transformer core. The results are shown in Fig.4. It can be seen that when the DC bias is applied, the magnetic flux of the three-phase three-limps transformer core is basically not affected by the DC bias, the amplitude does not increase significantly, and the waveform shows no significant distortion. This is because the DC magnetic flux is mainly closed by the leakage magnetic circuit and the core has no DC magnetic flux circuit.

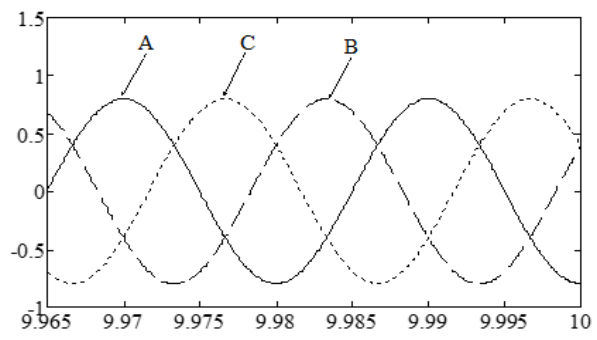

(b)

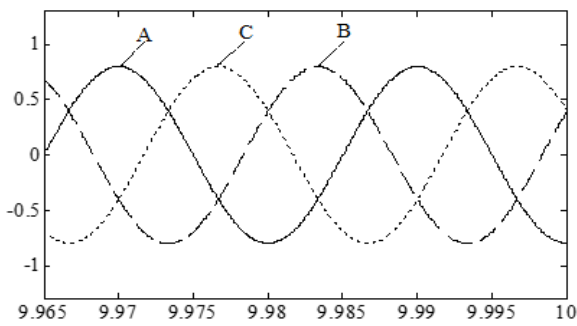

(a)

Fig. $4(\mathrm{a}) /(\mathrm{b})$ Core flux at IDC=0/24.8A

\section{Conclusion}

(1) Based on the EIC, J-A and Bertotti theory, the DC bias model of three-phase three-limps transformer is established. The model comprehensively considers the connection mode of core and winding, dynamic eddy current loss of core, core hysteresis loss, magnetic flux leakage and space 
coupling of coils, etc. And effectively solves the contradiction that both precision and complexity cannot be achieved.

(2) Based on this model, the influence of DC bias on the excitation current, leakage flux, and core flux of the three-phase transformer of $\mathrm{YN} / \mathrm{d}$ are analyzed. The results show:

1) With the increase of DC current, the DC bias magnetic flux has almost no influence on the excitation current of the three-phase three-limps transformer, the amplitude of each harmonic remains basically unchanged, and the odd harmonics are greater than the even harmonic content.

2) With the increase of the DC current, the magnitude of each harmonic of the leakage flux remains basically unchanged, and odd harmonic components are higher than even harmonic components. This shows that the increase of leakage flux is mainly due to the direct current component, and the leakage magnetic field AC component is basically unchanged.

\section{References}

[1]. LUO Zhi-jian, YE Jie-hong. Influence of harmonic on shunt capacitor in HVDC monopolar operation [J]. Power Capaciyor \& Reactive Power Compenstion, 2009, p. 58-61.

[2]. WEN Jun, LIU lian-guang, XIANG Song, Ma Xue-ling, LI Wei-xia. Influence of geomagnetic induced current on safe and stable operation of power grid. China Science and Technology Review, 2010, p. 24-30.

[3]. LI Xiao-ping, WEN Xi-shan, LAN Lei, etc. Test and simulation for single-phase transformer under DC bias. Proceedings Of The Chinese Society For Electrical Engineering. 2007, p. 33-40. 